\title{
FORMAÇÃO DE PROFESSORES UNIVERSITÁRIOS: NOVOS PARADIGMAS EPISTEMOLÓGICOS, OUTRAS PRÁTICAS
}

\author{
TRAINING OF UNIVERSITY TEACHERS: NEW EPISTEMOLOGICAL \\ PARADIGMS, OTHER PRACTICES
}

\begin{abstract}
Evódio Mauricio Oliveira Ramos
Doutor em Educação pela Universidade Estadual do Ceará. Professor Assistente do Departamento de Saúde da Universidade Estadual de Feira de Santana. Feira de Santana - BA - Brasil mauricioraoli@hotmail.com
\end{abstract}

Isabel Maria Sabino de Farias

Doutora em Educaçáo pela Universidade Federal do Ceará. Docente na Universidade Estadual do Ceará. Fortaleza - CE - Brasil isabelinhasabino@yahoo.com.br

\begin{abstract}
Resumo: $\mathrm{O}$ artigo analisa uma experiência formativa realizada em uma universidade pública baiana, apontando algumas contribuições pedagógicas dessa formação na prática dos docentes participantes. O grupo pesquisado foi constituído por 06 professores da referida universidade que participaram da formação pedagógica e o professor formador. O procedimento de coleta e produção de dados adotado foi a entrevista individual semiestruturada e o método de análise escolhido, a Análise Temática de Bardin (1977), tendo como categorias teóricas: identidade docente, profissionalização e modelos de formação pedagógica. Tomando como referência a abordagem qualitativa de cunho descritivo e com base nos achados da pesquisa, conclui-se que: a formação se constituiu como um fórum de reflexão, espaço dialógico que possibilitou ao docente universitário a ampliação de sua capacidade de ver, sentir, pensar, planejar, agir e avaliar sua ação pedagógica, dado o acesso propiciado a um novo paradigma epistêmico e metodológico, pautado na dialogicidade, criticidade, contextualidade e protagonismo dos sujeitos envolvidos no processo educativo. As açóes desenvolvidas na experiência formativa geraram mudanças significativas no uso de estratégias inovadoras de ensino, no processo de aprendizagem e de avaliação e na concepçáo epistemológica dos participantes, o que denota a relevância da formação pedagógica para a docência universitária, bem como a necessidade urgente de políticas institucionais de formação continuada para docentes que atuam no ensino superior.
\end{abstract}

Palavras-chave: Docência Universitária. Formação de Professores. Política de Formação.

Aвsтract: The article analyzes a training experience held in a public university in Bahia, pointing out some pedagogical contributions of this training in the practice of the participating teachers. The research group was composed of 06 professors from that university who participated in the pedagogical training and the teacher trainer. The data collection and production procedure adopted was the semi-structured individual interview and the chosen analysis method, the Thematic Analysis of Bardin (1977), having as theoretical categories: teacher identity, professionalization and pedagogical training models. Taking as a reference 
the descriptive qualitative approach and based on the findings of the research, we conclude that: the formation was constituted as a forum of reflection, a dialogical space that enabled to the university professor the amplification of his capacity to see, to feel, to think, to plan, act and evaluate their pedagogical action, given the access afforded to a new epistemic and methodological paradigm, based on the dialogicity, criticality, contextuality and protagonism of the subjects involved in the educational process. The actions developed in the formative experience generated significant changes in the use of innovative teaching strategies, in the process of learning and evaluation and in the epistemological conception of the participants, which denotes the relevance of pedagogical training for university teaching, as well as the urgent need for institutional policies of continuing education for teachers working in higher education.

KeYwords: University Teaching. Teacher Training. Training Policy.

\section{Introduçáo}

A crescente expansão do ensino superior no Brasil nos últimos tempos tem intensificado o debate sobre políticas de formação para a docência universitária. A necessidade de qualificação profissional, as novas configuraçôes do mundo do trabalho e dos empregos, dentre outros aspectos, têm desafiado a universidade a pensar uma formação que atenda às expectativas de desenvolvimento humano, de instrumentalização para o exercício profissional, de organização política, de produção de conhecimento e de gestáo pedagógica de novas tecnologias, mediante a articulação do ensino, da pesquisa e da extensáo. Essas expectativas têm desdobramento direto na formação de docentes e na organização do trabalho pedagógico.

Nessa perspectiva, este artigo analisa a relaçáo entre a experiência de formação pedagógica e a prática educativa dos docentes de uma universidade pública baiana, com enfoque nas repercussōes dessa ação na prática pedagógica. A metodologia está fundamentada na abordagem qualitativa de caráter descritivo, sendo utilizada entrevista semiestruturada como instrumento de coleta de dados e a Análise de Conteúdo para tratamento analítico dos dados.

De acordo com Bardin (1997), essa técnica pode ser descrita em três etapas básicas: a pré-análise, a descrição analítica e a interpretação inferencial. A pré-análise consistiu na organizaçáo do material de pesquisa que, em nosso caso, correspondeu ao registro e transcrição das entrevistas. $\mathrm{Na}$ segunda fase da técnica, a descrição analítica, o material foi submetido a 
um estudo aprofundado, tendo como parâmetro os objetivos da pesquisa e o referencial teórico utilizado. Foi elaborada, então, uma tabela que organizava e agrupava as categorias encontradas nas falas dos participantes, constando a categoria, o sujeito, seus depoimentos e algumas reflexóes e inferências iniciais dos pesquisadores, sem, contudo, haver aprofundamento das análises. $\mathrm{Na}$ terceira fase, de interpretação inferencial, partiu-se do material de pesquisa já organizado e seguiram-se os processos reflexivos e intuitivos dos pesquisadores, que avançaram para o estabelecimento de relaçóes entre a problemática pesquisada e a realidade apresentada nos discursos dos sujeitos.

A formação foi ofertada em 2011 no Departamento de Educação da Universidade Estadual de Feira de Santana, Bahia, pelo Núcleo de Estudos e Pesquisas sobre Pedagogia Universitária (NEPPU) em parceria com a Pró-Reitoria de Graduação (PROGRAD) e a Pró-Reitoria de Extensão (PROEX).

\section{Experiência de formaçáo: origem, contexto e concepçáo epistemológica}

Narrativas de vida e experiências têm importância fundamental no processo de autorreflexão, porque permitem nos situarmos em uma dimensão temporal, própria da experiência; e falar sobre elas, sendo parte do relato, permite expressar o vivido e o sentido. Tais saberes são fundamentais no processo educativo e na reconstrução do fazer pedagógico (CONTRERAS, 2011). A relação estabelecida entre saber e prática pedagógica a partir da experiência vivida funciona como um importante elo para a reflexão sobre a prática e para reformulaçóes nas açóes de ensino, pois constitui conhecimento vivido e aprendido que não se desliga da vida concreta, mas situa-se na história dos sujeitos, no seu tempo e no espaço.

É nessa perspectiva adotada por Contreras que, no presente escrito, discutimos experiência de formação envolvendo professores universitários de uma instituição pública, partindo da significação e dos sentidos dados pelos participantes ao processo educativo vivido. Nesse sentido, entende-se que a formação aconteça de forma processual, dinâmica e contextualizada, compreendida aqui como um continuum voltado para o desenvolvimento 
profissional do professor. Além de aspectos objetivos e subjetivos do seu trabalho, esse desenvolvimento possibilita aos docentes se apropriarem de saberes relacionados à sua atuação profissional e pessoal, pois vinculados à pessoa e sua identidade, experiência de vida e história profissional, suas relaçôes com os alunos em sala de aula e com os outros atores do processo educativo (TARDIF, 2010; CUNHA, 2010). Esse entendimento reforça a importância de uma formação que considere a prática já desenvolvida pelos professores e que, a partir dela, sejam oferecidos a eles meios para pensar novas ações didático-pedagógicas. É na articulação formação e prática que o professor poderá construir e consolidar seus saberes, refletindo sobre sua ação.

Nesses termos, a ideia da experiência formativa surgiu a partir da trajetória de uma professora - que aqui identificaremos como professora formadora $^{1}$ - e sua busca por caminhos que permitissem uma reflexão sobre os atos de planejar e avaliar dos docentes universitários. Sua inquietação com a concepção de ensino e de aprendizagem utilizada nas práticas educativas no meio acadêmico reverberou em outros espaços da universidade, oportunizando palestras, reunióes, seminários, fóruns e encontros de formação pedagógica sobre os fundamentos epistemológicos da avaliação e da aprendizagem. Esse movimento dentro da instituição desdobrou-se na elaboração de um Projeto de Extensão intitulado Avaliação da aprendizagem e desenvolvimento humano: implicações epistemológicas e metodológicas, formatado como um curso de 60 horas, aprovado no Conselho Superior de Ensino, Pesquisa e Extensão (CONSEPE) da Universidade (Resolução CONSEPE no 168/2006), cujo objetivo era criar um fórum de reflexão permanente para os professores universitários analisarem, refletirem e transformarem suas práticas.

A organização didático-metodológica da formação contemplava a articulação entre a formação teórica e a reflexão sobre a prática docente, com foco na análise do planejamento do professor cursista, na identificação de dificuldades e avanços sobre a proposta de aprendizagem e avaliação e nos encaminhamentos para a melhoria do trabalho docente. Durante os cinco anos de existência, essa experiência de formação envolveu muitos professores de diferentes departamentos da universidade, denotando uma grande demanda. Em 2011, foi realizada a última edição dessa experiência formativa, que contou com 18 inscritos, dos quais 10 concluíram o 
curso, sendo 03 professores e 07 professoras. Os docentes participantes da pesquisa são do quadro efetivo, com regime de trabalho de Dedicação Exclusiva (DE), tendo em média 15 anos de docência na instituição, com formação em bacharelado e, em sua maioria, pertencentes à área de saúde. $\mathrm{Na}$ última turma de formação, a carga horária de 60 horas foi dividida em 20 encontros de 3 horas, realizados durante o primeiro semestre letivo. Apesar do apoio de alguns órgáos da universidade e de sua implantaçáo como um programa de extensão, essa experiência foi finalizada em razão da aposentadoria da professora idealizadora e formadora. Os dados encontrados nesta pesquisa, somados a outros, podem oportunizar reflexôes que contribuam para a consolidação de uma política robusta de desenvolvimento profissional docente na instituição.

O debate sobre desenvolvimento profissional docente no Brasil, conceito relativamente novo na área da formação de professores, é impulsionado pela aproximação à produção de autores ibéricos como Imbernón (2010), García (1999) e Nóvoa (1999). Esses autores têm recorrido ao conceito na expectativa de "superar a tradicional justaposição entre formação inicial e aperfeiçoamento dos professores.” (GARCIA, 1999, p. 137) Argumentam que se trata de um conceito mais adequado à concepção do professor como profissional do ensino, evocando as noçóes de evolução e continuidade.

Os elementos explicitados evidenciam que o desenvolvimento profissional se centra na melhoria do professor, na construção e fortalecimento de sua identidade como docente, o que não se desvincula de avanços nas condiçóes materiais e subjetivas para o exercício da profissão. É assim que os autores supramencionados advertem também que fatores externos ao desempenho docente precisam ser conjugados a esse processo, sob o risco de fragilizar possíveis ganhos na qualidade do trabalho docente. Sob essa ótica, entendemos que são as condiçôes objetivas e subjetivas, aliadas a uma formação qualificada, que podem possibilitar uma prática docente mais coerente, criativa e emancipadora, bem como reflexão crítica sobre a relação entre conhecimento, práticas e experiências (LEITINHO, 2008). É necessário ressaltar ainda que não se trata de um investimento individual, uma ação caprichosa de um ou outro docente. Ao contrário, esse percurso precisa contar com uma política institucional que garanta investimentos na profissionalização e nas condiçôes necessárias de trabalho, 
numa ação que envolva o professor na pesquisa e na reflexão sobre suas práticas pedagógicas, que contemple, de forma integrada, as dimensóes epistemológicas, pedagógicas e políticas. (VEIGA, 2012)

Esses elementos conceituais deram suporte à realização da experiência formativa em foco neste escrito. Organizada a partir de vivências, estudos e discussões, essa ação de formação possibilitou aos docentes universitários envolvidos a superação da lógica formal por uma lógica dialética, cuja base teórica está fundamentada em Anastasiou e Alves (2005); Becker (2003); Hoffmann (2001); Luckesi (2002); Pozo (2002); Tyler (1974); Vasconcelos (1995); Veiga (1996) e Zanella (2004), entre outros. Segundo a professora formadora, a intenção era provocar uma autorreflexão do docente acerca de sua prática e de seus princípios didático-metodológicos, refletindo em autoaprendizado, autoavaliação e instrumentalização para a intervenção pedagógica, bem como a procura de respostas aos problemas da prática educativa. Todo o processo buscava, sempre, refletir sobre a concepção de aprendizagem e sobre os elementos ontológicos, metodológicos e epistêmicos que a compóem. A formação tomou o protagonismo de cada professor como princípio, propiciando a eles compreender a relação intrínseca e inseparável do que sejam objetivos, conteúdos e estratégias de aprendizagem, processo avaliativo, leitura do social e desenvolvimento humano. Nesse sentido, buscou-se desafiar, estimular e apoiar os professores na construção de uma relação com o objeto de aprendizagem que, em algum nível, atendesse a suas necessidades, auxiliando-os na reflexão sobre a ação pedagógica e tomadas de decisão (ANASTASIOU; ALVES, 2005). De acordo com a narrativa da professora formadora, também participante desta pesquisa e identificada como Lucile Ruth, as discussóes sobre e a partir das experiências levaram a amadurecimento epistemológico sobre estratégias de ensino, tanto do ponto de vista da experimentaçáo do professor participante quanto da aplicação dessas estratégias no contexto de sala de aula, sendo um suporte importante no aprendizado e na definição de novas estratégias didáticas que promovessem o aprendizado dos estudantes, a melhoria da qualidade da ação pedagógica docente e a satisfação dos professores no exercício da docência.

No tópico seguinte apresentamos algumas contribuiçóes dessa experiência na prática docente, segundo a visão dos professores envolvidos. 


\section{Contribuições da formação na socialização entre professores}

Inicialmente, o ato docente é identificado, pelo grupo pesquisado, como uma experiência muito estressante e solitária, mesmo considerando as tentativas de trabalho em equipes interdisciplinares e multidisciplinares. Diante das circunstâncias de isolamento, pressôes e cobranças vivenciadas por esses professores no exercício da docência universitária, a formação, segundo a professora participante Tâmara ${ }^{2}$, possibilitou a aproximação entre colegas e a superação das dificuldades:

As angústias não são só minhas, as dificuldades não são só minhas, são dos outros e outros e outros... Mostra que realmente aquilo é parte do processo. E a partir daí, vai nos dando caminhos e diretrizes para a gente ir resolvendo. Esse compartilhar é excelente (Tâmara).

O acolhimento ao grupo e o afeto entre participantes foi uma das situaçôes significativas apontadas pelos professores que geraram um sentimento de bem-estar e segurança, favorecendo a trocas de saberes. Charlier (1998) aponta que as experiências do compartilhar reflexivo com as vivências dos colegas, em consonância com os aportes teóricos, fomentam o debate sobre as práticas e seu amadurecimento. Sobre essa partilha os professores afirmaram:

[...] propicia a possibilidade de conhecer nossa realidade a partir do olhar e das experiências de outros, de aprender com o outro, de entender como é que o outro enfrenta, supera, ignora, age ou reage! Essa possibilidade de troca, de partilha da sua experiência é muito importante! Porque essas trocas sempre enriquecem. (Daniela)

Pra mim esses momentos serão sempre um desabafo! Quando eu falava da minha experiência me sentia aliviada e acolhida pelos colegas. (Neusa) 
Um aspecto destacado nas falas dos professores foi a contribuição da formação para que experimentassem a dimensão coletiva e solidária de sua existência como humanos, táo importante nos processos formativos (SEVERINO, 2003). Oriundos dessa experiência de partilha, o contato afetivo, o aprendizado e a aproximação da realidade do colega colaboraram para a manifestação desse sentimento:

As experiências de trocas são interessantes! Criam uma irmandade e cumplicidade no sentido de se o outro também passa pelo que eu passei ou eu também posso passar o que ele tá passando. Acho que isso humaniza as relações entre os professores, e, nos humaniza no sentido da gente saber acolher o aluno. Esse aprendizado de humanização foi algo muito importante. (Daniela)

Além da possibilidade de humanização das relaçóes interpessoais e de acolhimento entre os integrantes do grupo, os professores crescem com os relatos dos colegas, caracterizando um processo de formação partilhada. Essa troca de feedback foi possível por meio da socialização oportunizada, experiência comum em modelos de formação que trazem em suas metodologias atividades baseadas no trabalho em grupo, no apoio mútuo, no diálogo horizontalizado, na partilha e na reflexão coletiva.

Destacamos as reverberaçóes do processo de socialização em outros espaços acadêmicos, por exemplo, a abertura do debate da docência no Ensino Superior e a organização do trabalho pedagógico nos colegiados de Medicina, Odontologia, Informática e Enfermagem. Muitos espaços de discussão foram instalados decorrentes da participaçáo dos professores nessa experiência formativa e da divulgação da qualidade de seus conteúdos. De acordo com a professora formadora,

[...] esses elementos nos levam a perceber que uma pedrinha foi jogada na água e reverberou, os fóruns estabelecidos em um curso de extensão começam a penetrar nas veias de atuação da universidade, onde corre a vida acadêmica. (Lucile Ruth) 
Nessa perspectiva, cria-se um ambiente de reflexão da prática dos professores e uma mobilização entre os pares para os processos de desenvolvimento profissional dentro da instituição.

\section{Contribuiçóes da formação no aprendizado dos estudantes}

O desenvolvimento profissional docente, especificamente a ação de formação e aperfeiçoamento, não afeta só o professor. De acordo com Cunha (2010), todos os envolvidos no processo educativo são beneficiados, na medida em que acontece a melhoria da qualidade do saber docente. Com a ampliação dos saberes pedagógicos e dos conhecimentos específicos, a compreensão do papel histórico da profissão e a melhoria das relaçôes afetivas entre os envolvidos, tanto estudantes e professores quanto instituição de ensino conseguem meios para atingir seus objetivos de forma eficaz. Na visão das professoras Tâmara e Neusa, além de ser percebido esse crescimento no aprendizado, o mesmo vem como consequência da melhoria do trabalho docente:

$\mathrm{Na}$ medida em que fui encontrando respostas pra minhas angústias, pra minhas inquietaçôes, eu fui modificando algumas coisas, acredito que os alunos também tenham aferido alguns ganhos em relação a isso (Tâmara).

Quando o professor compreende seu papel, a aprendizagem vem naturalmente. Porque o que a gente quer é que no final o aluno apreenda. No momento em que o professor muda sua postura, o resultado final vem (Neusa).

É preciso ressaltar que, ao falarmos dessa melhoria no ensino, não a estamos reduzindo à relação de sala de aula, mas a todo o contexto que circunscreve essa prática. De acordo com Severino (2003), as condições de trabalho e de salário, dentre outros aspectos, degradam e precarizam a atividade de ensino e, portanto, precisam ser consideradas nesse debate, compondo o conjunto de açóes de uma política de desenvolvimento pro- 
fissional. Devido à finalidade e especificidade desta análise, centramos a discussão no professor, sem, contudo, desconsiderar outros elementos que envolvem a docência.

Saviani (2005) e Freire (2011) asseveram que mudanças na ação docente implicam maior responsabilidade afetiva, ética e política dos professores com a formação dos estudantes e a transformação de suas realidades. Ao aproximar-se do estudante com esse compromisso, o professor pode contribuir qualitativamente com seu aprendizado. Para os professores, o uso de estratégias ativas, que geram maior interesse e participação dos estudantes na construção dos conhecimentos e de sua formação, de modo geral, propicia melhores resultados.

Foram destacadas duas estratégias de aprendizagem experimentadas pelos professores na formação: os mapas conceituais e os diários reflexivos. Segundo Anastasiou e Alves (2005), os mapas conceituais consistem na criação de um diagrama pelo qual professores e estudantes estabelecem uma relação bidimensional e hierárquica entre os conceitos apresentados no conteúdo; já os diários reflexivos são caracterizados como instrumentos de registro permanente dos conhecimentos apreendidos, ou ainda em construção, e são estratégias importantes no processo educativo, definindo estratégia, de acordo com as mesmas autoras, como a arte de aplicar ou explorar os meios e condições favoráveis e disponíveis visando à efetivação da ensinagem ${ }^{3}$ (ANASTASIOU; ALVES, 2005).

Essas estratégias permitem um movimento, fundamentado no método dialético, de síncrese, análise e síntese que permite ao sujeito se colocar como autor e responsável, associando sentimentos, pensamentos e novos discursos, que por sua vez farão parte de novas sínteses (ANASTASIOU, 2008).

Sobre a escrita dos diários e a elaboração dos mapas conceituais, Contreras (2011) e Shön (2000) admitem que aprender a experimentar e aprender a refletir sobre suas ações é fundamental para elaboração de sínteses próprias. Experiências que promovam a reflexão-na-ação e sobre a ação, no uso de estratégias como o diário reflexivo, possibilitam a ampliação do conhecimento e a visão de mundo do grupo. O uso dessas estratégias propiciam um salto qualitativo extraordinário no desenvolvimento formativo dos professores e estudantes. Para a professora Rosângela e Tâmara, o uso dos diários reflexivos em suas aulas oportunizou a melhoria da capacidade de reflexão e de aprendizagem: 
Quando a gente vai construir o diário, a gente retoma os conteúdos. E ao retomar, a gente faz a reflexão e consegue aprender direito, aprofundar mais e dar conta de coisas que não estáo claras para a gente. (Tâmara)

[...] o diário foi um momento de refletir sobre o que eu faço, o que eu posso melhorar, eu acho que foi nesse sentido que mobilizou. (Rosângela)

\section{Contribuiçóes da formação para a adoçáo de práticas inovadoras}

Chamamos aqui de práticas inovadoras as atividades didáticas significativas realizadas pelos professores, durante ou após a formação vivenciada, apontadas como exitosas, ou seja, estratégias que promoveram um melhor aprendizado dos estudantes. A ação relatada pela professora Tâmara, que divide a disciplina que leciona com outros colegas, reporta-se ao uso de outra estratégia de avaliação:

Nós fizemos uma experiência com a avaliação. Ao invés de fazer uma prova tradicional, nós construímos um tribunal de júri em cima de certa situação de ensino e aprendizagem. Foi muito rica e interessante! (Tâmara)

$\mathrm{Na}$ realização da avaliação de uma concepção e prática formativas, os instrumentos e critérios assumem uma perspectiva de regulaçáo da aprendizagem em que a metacognição é preponderante, ao invés da quantificação do conhecimento. Esse processo consiste nos mecanismos de controle e ajuste do aluno sobre seus próprios processos de aprendizagem (ANASTASIOU; ALVES, 2005). Nesse sentido, inovar o processo avaliativo foi um dos aspectos mais citados pelos professores, o que demonstra coerência com as necessidades formativas apontadas pela maioria do grupo. Para os participantes, a avaliação é o elemento da organizaçáo do trabalho pedagógico mais complexo e desafiador. Convém destacar que não é percebido apenas o uso de instrumentos variados ou diferenciados para avaliar. Fruto do debate epistemológico, nota-se uma mudança na 
concepção de avaliação que deixa de ser meramente classificatória e quantificadora e passa a ser vinculada ao processo de aprendizagem.

O uso do portfólio, estratégia que segundo Anastasiou e Alves (2005) permite o registro, análise, seleção e reflexão de produçôes mais significativas, bem como a identificação dos desafios e dificuldades em relação ao objeto de estudo e aos mecanismos de superação dessas dificuldades, permitiu aos professores considerarem o trabalho avaliativo e de produçáo de conhecimento de forma processual, superando a concepção reducionista das provas e de aulas expositivas, "integrando-o no contexto de ensino como uma atividade complexa baseada em elementos de aprendizagem significativa e relacional." (ANASTASIOU; ALVES, 2005, p. 115) Para os autores, a ação de aprendizagem passa a pertencer ao estudante na medida em que ele se torna o protagonista do seu aprendizado decidindo quais trabalhos e momentos são representativos em sua trajetória formativa. A formação possibilitou um maior conhecimento e fundamentação para o uso dessa estratégia pedagógica e, consequentemente, um melhor envolvimento dos estudantes no processo de aprendizagem e de avaliação.

Alguns professores náo reconhecem alteraçóes em sua prática pedagógica a partir do processo de formação vivido, todavia, em suas falas identificamos evidências de fissuras em certas convicçóes, a exemplo da forma de conceber o processo avaliativo e a maneira como o sujeito aprende. Nota-se nesses excertos movimentos de alteração ainda não claramente compreendidos pelos docentes, mas que evidenciam que certezas instituídas foram colocadas em causa, abertura fundamental para que modificaçóes substantivas no modo de pensar e de agir possam se firmar, denotando uma alteração epistemológica importante. Nesses termos, a formação vivida no contexto institucional aqui destacado gerou possibilidade de renovação do repertório de conhecimentos e práticas dos professores, contribuindo teórica e conceitualmente para a reflexão dos modelos de ensino que eram adotados.

Este fato denota, ainda, que o desenvolvimento profissional requer investimentos contínuos, pois o processo de mudança, a depender do nível de dificuldade e do grau de interesse de cada participante, requer tempo e espaço pedagógico que, em geral, não coadunam com a imediaticidade das políticas. Para a professora formadora, essa experiência de formação não pode se restringir a esse momento isoladamente. Há necessidade de uma 
formação permanente para que o professor possa consolidar os conhecimentos adquiridos. Noutras palavras, faz-se necessária uma política permanente de desenvolvimento profissional docente na instituição, sinaliza a professora. Para Anastasiou e Alves (2005), o saber-fazer exige contínua possibilidade de troca, de abertura, de busca de solução das dúvidas e de permanentes reflexóes para que esse novo conhecimento seja integrado ao cotidiano. Essa ideia de ampliação dos espaços de reflexão após a experiência formativa é defendida pela professora formadora:

O professor começa a ousar, inovar, embora nem tenha consciência dessa inovação ainda. Por que eu acho que esse fórum precisa continuar e o professor precisa sentir livre pra retomar pra essa discussão. (Lucile Ruth)

Em geral, as ações relatadas servem como referência de possíveis melhorias do processo educativo. Diante das circunstâncias e limitaçóes desse espaço de formação, podemos identificar referências necessárias para as mudanças concretas no avanço do ensino na universidade.

\section{Contribuiçóes da formaçáo no processo avaliativo}

No que diz respeito à forma de avaliação a que os participantes foram submetidos durante a experiência de formaçáo, a proposta, de acordo com a professora formadora, sempre partiu da compreensão do olhar do professor, de suas representaçóes. Os diferentes instrumentos avaliativos buscavam a expressão dos sujeitos, possibilitando que manifestassem seus sentimentos e ideias, para, a partir dai, instaurar um processo de autorregulação e autoavaliação. Segundo Bélair (1998), essas características são inerentes àquele que analisa sua prática, reflete e age sobre ela, buscando rever permanentemente suas ações na tentativa de encontrar sentidos e significados. Sobre a estratégia, a professora formadora pondera:

[...] a observação, a escuta, foram instrumentos que me auxiliaram muito na coleta de dados. Eu estava muito atenta ao que ele falava, buscando que ele se autorregulasse e, essa é uma nova 
lógica de pensar a avaliação. Uma nova tela crítica. O diário reflexivo e a observaçáo foram elementos que alimentaram uma avaliação mais qualitativa. (Lucile Ruth)

A reflexão sobre a prática permitiu à professora formadora inferir a qualidade dos debates provocados durante a formação e os impactos dessas reflexóes na atuação docente. Seus depoimentos trazem registros significativos dos avanços dos professores no que diz respeito à mudança de perspectiva da docência, uso de inovaçóes metodológicas em sala de aula e uma atuação pautada numa concepção teoricamente consolidada. Além disso, pode-se inferir que os professores encontraram nessa experiência um espaço de escuta de seus fazeres, de suas dúvidas, de suas histórias, o que quase nunca acontece com o docente do ensino superior, que na maioria das vezes trabalha isolado entre as paredes da sala de aula ou dos laboratórios. Segundo a professora formadora:

Professores que participaram da formação, não são mais os mesmos. [...] saíram dizendo que essa formação pedagógica mudou sua atuação docente. Eles traziam para o próprio curso as inovaçóes que realizavam na sala de aula. Uma professora do Departamento de Letras disse: - Vocês conseguiram me tirar do "piloto automático". O que eu percebo na fala dos professores que encontrei posteriormente, é que eles dizem que aquele curso mudou suas vidas. (Lucile Ruth)

Em sua ótica, é preciso valorizar a questão qualitativa na avaliação. De acordo com a formadora "Os professores que passaram pela experiência formativa poderão provocar novas reverberaçóes onde estiverem, podem vir a ser aquela sementinha constante, ou então aquela água levada para que a sementinha brote", afirma. Sua declaração está carregada de esperança e utopia, uma utopia de quem sonha, esperançosamente, com a mudança. Desde quando projetou a experiência vislumbrava a possibilidade de fazer uma formação continuada com os docentes da universidade.

Umas das estratégias mais utilizadas na formação para avaliação dos aprendizados foi o diário reflexivo. Esse instrumento, segundo a professora formadora, permitia ao professor refletir sobre sua atuação prática. 
Os diários eram elaborados e organizados a partir de questôes que faziam os professores articularem o tema trabalhado, seu nível de conhecimento, a interação com sua prática e outras dúvidas e inquietaçôes. $\mathrm{O}$ que você aprendeu? O que foi mais relevante? Sobre o que você tem dúvida? O que você leu? $\mathrm{O}$ que precisa melhorar? Essas questóes permitiam um espaço de reflexáo e trocas. Para a professora formadora, os diários permitiram avaliar o quanto os participantes estavam se desenvolvendo profissionalmente, sempre buscando adequar o momento formativo às necessidades e condiçôes objetivas dos professores.

A representação dos professores acerca do uso dos diários reflexivos denota a riqueza dessa experiência, como possibilidade de crescimento e aprofundamento cognitivo dos temas, da reflexão sobre o que faziam nas aulas e o que poderiam melhorar, o sentimento de partilha e ampliação da visão do individual para o coletivo. As declaraçóes das professoras Tâmara, Rosângela e Daniela representam essa avaliação:

Quando a gente vai construir o diário, a gente retoma os conteúdos. E ao retomar, a gente faz a reflexão e consegue aprender, aprofundar mais e dar conta de coisas que não estão claras para a gente. (Tâmara)

[...] deu pra fazer uma reflexão e também ir criando como possibilidade de usar esse diário numa disciplina que tem cento e vinte horas. O diário foi um momento de refletir sobre o que faço, o que posso melhorar, foi nesse sentido que mobilizou. (Rosângela)

[...] você fazia uma reflexão, mas do que isso, sua implicação no conteúdo. Acho interessante quando você se implica, é uma forma de você fazer o aluno ou você ou eu como aprendiz de pensar enquanto aprendiz e sujeito no processo. (Daniela)

Em contrapartida, foram identificadas pelos professores duas dificuldades, quando se pensa no uso do diário reflexivo com os estudantes: primeiro, quando utilizado como única referência avaliativa, pode ser uma estratégia geradora de acomodação por ficar repetitiva; segundo, falta tempo a estudantes e professores para o preenchimento dos diários. 
Eu acho uma ideia legal os diários reflexivos, mas só que a gente tem dois problemas: o aluno tem muita aula e o professor dá muita aula. $\mathrm{O}$ aluno tem que sentar em casa, tem que ter algum momento pra ele refletir, coisa que não há tempo. Então, esse método atrasado brasileiro impede a implantação desse diário reflexivo. (Bernardo)

Para as questôes apontadas, o professor Bernardo sugere a implantação de um diário reflexivo digital visando dinamicidade e eficácia no uso do diário reflexivo em atividade com os estudantes. Sobre essa questão, Anastasiou e Alves (2005) trazem como possibilidade os webfólios, que teriam como ação a disponibilidade de troca de materiais em homepage, uso de softwares interativos, fóruns on-line, postagem de relatos, dentre outros. Para esses autores, a ferramenta possibilita o acompanhamento do modo como cada estudante aprende conceitos, procedimentos e atitudes relacionados à disciplina, oportunizando um processo de reflexão sobre o fazer discente e docente. A reflexão sobre a escrita de processos, sobre as questóes e desafios lançados pelo professor permite um avanço no desenvolvimento de cada estudante. (ANASTASIOU; ALVES, 2005)

\section{Consideraçóes Finais}

$\mathrm{O}$ artigo discutiu as relaçóes entre a formação pedagógica vivenciada em uma universidade pública baiana e a prática dos professores, experiência retratada como importante mecanismo de reflexão da praxis dos docentes.

Os achados de pesquisa permitiram compreender: os pressupostos epistemológicos e metodológicos que referenciaram a experiência formativa; a relação existente entre a formação pedagógica que esses sujeitos vivenciaram e as mudanças ocorridas em suas atitudes e práticas educativas; as contribuiçóes da formação para pensar estratégias que viabilizem a melhoria da qualidade do ensino; os desafios de mudança de paradigmas epistemológicos, tanto no processo de ensino quanto no de avaliaçáo da aprendizagem.

A formação surge num contexto de necessidades pedagógicas e apresenta possibilidades de superação do ensino formal pela reflexão epistemológica. Aproxima o professor de uma prática dialética, cuja estratégia pe- 
dagógica pode melhorar o desenvolvimento e a formação profissional dos estudantes. Nesse sentido, a formação cumpriu seu papel como fórum de reflexão, espaço dialógico que possibilitou ao docente a ampliação de sua capacidade de ver, sentir, pensar, planejar, agir e avaliar sua ação pedagógica.

Os professores participaram da formação movidos por interesses pessoais e sem incentivo da instituição, vislumbrando mudanças no ato pedagógico e a resolução de problemas metodológicos do cotidiano acadêmico. Mergulharam epistemologicamente no processo dialético da 'reflexão-sobre-a-reflexão-na-ação', demonstrando crescimento e amadurecimento profissional. A partir do saber da experiência, indicaram a construçáo de redes conceituais e de algumas perspectivas - nos aspectos teórico-metodológicos e relacionais -, repensando as dimensóes afetivas e o processo humanizador da educação. A partir da análise dos depoimentos, é possível constatar que a experiência de partilha e de socialização possibilitou a vivência dos sentimentos de acolhimento, afeto e cumplicidade, propiciando redes de aprendizagem e de parceria solidária.

Sobre os desdobramentos da formação pedagógica em relação ao aprendizado dos estudantes, os docentes apontam inovações e estratégias de ensino que repercutiram de forma salutar na interação, na motivação e no crescimento pessoal, profissional e acadêmico dos estudantes, apesar do contexto adverso no qual esses profissionais desenvolvem a docência. $\mathrm{O}$ uso do portfólio, do diário reflexivo, de mapas conceituais, de redes conceituais e de dinâmicas relacionais, dentre outras estratégias, serviu como processo dialético de mão dupla que potencializa a compreensão do ato de aprender e de fazer, exercitando o sentimento de se colocar no lugar do aprendente.

Todavia, ainda que discretas e pontuais, as atividades geraram mudanças e denotam a importância da referência teórica e da formação pedagógica para atuação nesse nível de ensino, provocadas por momentos de reflexão epistêmica nessa experiência formativa. O que nos faz concluir sobre a necessidade urgente de políticas institucionais de desenvolvimento profissional de docentes que atuam no ensino superior, tendo em vista a demanda por formação no campo pedagógico. E que essas ações possam contribuir para que os docentes reflitam sobre as transformaçóes paradigmáticas necessárias em suas práticas com vistas à formação integral dos estudantes que estão adentrando à universidade. 
A formação nessa perspectiva não deve estar embasada nos moldes de treinamento empresarial que visam o utilitarismo profissional e a produtividade. Mas um programa institucional que supere a lógica operacional imposta pelos organismos internacionais e pelos órgãos de fomento ao aperfeiçoamento profissional para o Ensino Superior, regulada pela eficiência, eficácia, controle e competitividade. $\mathrm{O}$ essencial nesse processo é que haja uma melhor política de valorização do trabalho docente, bem como a garantia das condiçóes desse trabalho, como condição de possibilidade para a melhoria do processo de ensino e aprendizagem na universidade. (VIEIRA, 2009)

Assim conduzida, a formação poderá contribuir para os professores acreditarem que, apesar da complexidade, a docência pode ser qualificada pela reflexão epistemológica sobre o ato de aprender, a investigação das práticas, a identificação dos saberes que necessitam adquirir com vistas a promover o seu próprio desenvolvimento profissional, para, dessa forma, agirem com profissionalismo em uma atividade que requer formação específica de natureza didático-pedagógica.

\section{Notas}

1 Profa. Lucile Ruth Menezes - Docente que atuou no Departamento de Educação/UEFS até sua aposentadoria em 2012, idealizadora e professora formadora do curso de formação pedagógica "Ensinagem, Aprendizagem e Avaliação no Ensino Superior". Mestra em Música e Educação, Especialista em Psicopedagogia, em Neuropsicologia e em Avaliação.

2 Os codinomes utilizados nesse trabalho são fictícios, tendo por finalidade a preservação de identidade e da privacidade dos professores pesquisados.

3 Termo cunhado pelas autoras para denotar um movimento singular e processual no ensinar dentro do ato educativo.

\section{Referências}

ANASTASIOU, L. das G. C. Desafios da docência universitária em relação a algumas bases teórico-metodológicas do ensino de graduação. In: RIBEIRO Marinalva; SOARES, Sandra R.; MARTINS, Édiva de S.; MAHEU, Cristina d'A. (Org). I Colóquio Internacional sobre Ensino Superior. Ensino Superior: complexidade e desafios na contemporaneidade. Feira de Santana, BA, 2008. 
ANASTASIOU, L. das G. C; ALVES, L. P. Estratégias de ensinagem. Joinville: UNIVILLE, 2005.

BECKER, F. A origem do conhecimento e a aprendizagem escolar. Porto Alegre: Artmed, 2003.

BÉLAIR, L. A formação para a complexidade do ofício de professor. In: PAQUAY, L; PERRENOUD, P; ALTET, M; CHARLIER, E. (Org.). Formando professores profissionais: quais estratégias? quais competências?. 2. ed. Revista. Porto Alegre: Artmed, 1998. p. 54-65.

BARDIN, L. Análise de conteúdo. Lisboa: Edições 70, 1997.

CHARLIER, E. Formar professores profissionais para uma formação contínua articulada à prática. In: PAQUAY, L; PERRENOUD, P; ALTET, M; CHARLIER, E. (Org.). Formando professores profissionais: quais estratégias? quais competências?. 2. ed. rev. Porto Alegre: Artmed, 1998. p. 85-102.

CONTRERAS, J. D. Experiencia, escritura y deliberación: explorando caminos de libertad em la formación del profesorado. In: ALLIAUD, A; SUÁREZ, D. H. (Coord.). El saber de la experiência: narrativa, investigación y formación docente. Buenos Aires: Consejo Latinoamericano de Ciencias Sociales - CLACSO, 2011.

CUNHA, A. F. Docência superior em foco: articulações entre formação continuada, saberes e práticas pedagógicas. 2010. 152 f. Dissertação (Mestrado em Educação) Fundação Universidade Federal do Piauí, Teresina. 2010.

FREIRE, P. Pedagogia da autonomia: saberes necessários à prática educativa. São Paulo: Paz e Terra, 2011.

GARCÍA, Carlos Marcelo. Desenvolvimento profissional docente: passado e futuro. Revista de Ciências da Educação Sísifo, n. 08, p. 7-22, jan./abr. 2009.

Editora, 1999.

Formação de Professores: para uma mudança educativa. Porto: Porto

HOFFMANN, J. Avaliar para promover: as setas do caminho. 2. ed. Porto Alegre: Mediação, 2001.

IMBERNÓN, Francisco. Formação continuada de professores. Porto Alegre: Artmed, 2010.

LEITINHO, Meiricele Calíope. A formação pedagógica do professor universitário: dilemas e contradiçóes. Linhas Críticas, Brasília, v. 14, n. 26, p. 79-92, jan./jun. 2008.

LUCKESI, C. C. Avaliação da aprendizagem na escola: reelaborando conceitos e recriando a prática. Salvador: L. C. C., 2002.

NÓVOA, Antônio. Os professores e sua formação. 4. ed. Porto, Portugal: Porto Editora, 1999. 
POZO, J. I. Aprendizes e mestres: a nova cultura da aprendizagem. Porto Alegre: Artmed, 2002.

SAVIANI, D. As concepções pedagógicas na história da educação brasileira. Campinas, 2005. Disponível em: <http://www.histedbr.fae.unicamp.br>. Acesso em: 14 abr. 2013.

SEVERINO, A. J. Preparação técnica e formação ético-política dos professores. In: BARBOSA, R. L. L. (Org.). Formação de educadores: desafios e perspectivas. São Paulo: Editora UNESP, 2003. p. 71-89.

SHÖN, D. A. Educando o profissional reflexivo: um novo design para o ensino e a aprendizagem. Porto Alegre, Artes Médicas - Sul, 2000.

TARDIF, M. Saberes docentes e formação profissional. 11. ed. Petrópolis: Vozes, 2010.

TYLER, R. W. Princípios básicos de currículo e ensino. Porto Alegre: Globo, 1974.

UEFS, Conselho Superior de Ensino, Pesquisa e Extensão (CONSEPE) - Resolução CONSEPE no 168/2006, 2006.

VASCONCELOS, C. dos S. Avaliação concepção dialética - libertadora do processo de avaliação escolar. São Paulo: Libertad, 1995.

VEIGA, I. P. A. Universidade e desenvolvimento docente: propostas em debate. Araraquara, SP: Junqueira \& Marin, 2012.

. Técnicas de ensino: por que não? Campinas: Papirus, 1996.

VIEIRA, F. Em contracorrente: o valor da indagação da pedagogia na universidade. Revista Educação, Sociedade \& Culturas, n. 28, p. 107-126, 2009.

ZANELLA, A. V. Atividade, significação e constituição do sujeito: consideraçôes à luz da psicologia histórico-cultural. Psicologia em Estudo, Maringá, v. 9, n. 1, p. 127-135, 2004.

Recebido em 27 set. 2017 / Aprovado em I5 out. 2018 Para referenciar este texto:

RAMOS, E. M. O.; FARIAS, I. M. S. Formação de professores universitários: novos paradigmas epistemológicos, outras práticas. EccoS - Revista Científica, São Paulo, n. 47, p. 317-336. set/dez. 2018. Disponível em: <https://doi.org/10.5585/EccoS. n $47.7873>$. 